\title{
Optimal control of a double-barbane water-tube boiler
}

\author{
Andrey Smolyaninov ${ }^{1, *}$, Irina Pocebneva ${ }^{1}$, Kirill Garmonov ${ }^{1}$, and Alexander Bahmetev ${ }^{1}$ \\ ${ }^{1}$ Voronezh State Technical University, 394006, 20-letiya Oktyabrya Street, 84, Voronezh, Russia
}

\begin{abstract}
The article discusses the synthesis of a control system that implements optimal control of a double-drum water-tube boiler with natural circulation with effective suppression of disturbing influences and ensuring astatism of the control channel. One of the main channels of the object is described in the most detail, the channel "fuel consumption pressure of superheated steam", which is decoupled from others. Therefore, it is for him that we will carry out the calculation of the automatic control system (ACS), the reaction of the system to a stepwise disturbing effect is indicated. Using the method of mathematical modeling, the operability of the synthesized control system was confirmed, its operability when the parameters of the model were varied twice, which indicates the possibility of transition from model to physical tests of the proposed control algorithm.
\end{abstract}

\section{Introduction}

The idea of using water vapor for industrial needs dates back to the second half of the eighteenth century. It was then that the Russian inventor I.I. Polzunov invented the first industrial steam boiler.

Over the years since then, boiler construction has made great strides forward: the steam output of the boilers has increased to $2500 \mathrm{t} / \mathrm{h}$, the steam pressure of powerful boilers has increased to $255 \mathrm{~atm}$, and the steam temperature to $540-570{ }^{\circ} \mathrm{C}$. And at present, industrial steam has begun to be used not only for the technological needs of enterprises, but has become one of the main means of generating electricity on turbines.

So at the CHP enterprise, part of the steam produced by boiler units goes to factories for industrial needs, the other part of the steam goes to boiler plants, deaerators, high and low pressure heaters, process water heaters and for the company's own needs, and the bulk of steam goes to steam blades turbines, where it performs work on their rotation and thereby produces electricity, which supplies a significant part of the city [1].

The development of an automated control system for double-drum water-tube boilers with natural circulation used at CHP enterprises is of great practical importance for the modernization of thermal power plants. It should also be noted that the reliable and economical operation of the boiler plant largely depends on the quality of the water used to power the steam boilers. Thus, before being supplied to the boiler, natural water must be subjected to special treatment in water purification devices, because it should not form

* Corresponding author: u00781@vgasu.vrn.ru 
deposits of sludge and scale, should not corrode the walls of the boiler and its auxiliary heating surfaces, and should not foam. It is then that the correct operation of the boiler unit is possible [2].

When considering the generalized technological scheme of a CHP plant, the following main equipment can be whitened - these are steam boilers and turbines. Further in the article, we will consider in more detail the device of a double-drum water-tube boiler with natural circulation, which is necessary for building an automated control system.

\section{Experimental}

The double-drum water-tube boiler with natural circulation has a U-shaped arrangement, in which the first ascending flue is a combustion chamber, and a water economizer and an air heater are located in the second descending flue. On the side walls of the furnace there are 8 vortex gas burners. ( 4 on each wall). The burners are arranged in 2 tiers - 3 in the upper tier, 1 in the lower tier. To supply combustion air and exhaust flue gases, respectively, two blowing fans and two smoke exhausters are installed. This boiler unit is designed to operate both on gas and on fuel oil and pulverized coal. In this project, only gaseous fuels will be considered, since it is a more rational and economical fuel type [3].

Consider the technology of steam production at the boiler unit under consideration. From the common collector, the feed water enters the water economizer [4] (2 stages in sequence), heating up to a temperature of about $230^{\circ} \mathrm{C}$. Then the feed water enters the boiler drum to the distribution chute. Further, through the water-lowering pipes, it enters the lower collecting headers and then into the screen pipes located directly in the boiler furnace. The steam-water mixture formed in the wall tubes enters the upstream drum of a smaller diameter. Here the preliminary separation of steam and water takes place, which are transferred to the main drum through steam and water transfer pipelines. In the drum, the water is finally separated from the steam and sent back to the downpipes. This movement of water is called natural circulation, and it is due to the difference in the density of water in unheated areas and the steam-water mixture in heated areas. The lower part of the drum (about half) is filled with water and the level is kept constant. Thus, water flows by gravity many times through the pipes. Saturated steam from the drum is fed to the superheater. Having passed the heating surface of the superheater, the saturated steam is superheated and dried and then, having the specified parameters, enters the common steam line [5].

The drum of this boiler unit is equipped with separation devices: internal cyclones, louvered separators, perforated sheet, designed to completely separate water droplets from steam and thus obtain clean steam. To remove dissolved substances, steam in the upper part of the boiler drum passes through a layer of feed water, in which these substances dissolve and together with them merge into the volume of boiler water, where the content of dissolved substances is allowed to be higher than in steam [6].

\section{Evaluation}

A steam boiler is a complex unit [7], and the technological processes of fuel combustion and production of steam of a certain quality are characterized by several parameters of various physical nature and magnitude, as a rule, interconnected by certain relationships.

The main output parameters of the boiler are as follows:

- water level in the boiler drum;

- temperature of superheated steam;

- superheated steam pressure.

The input parameters are: 
- consumption of feed water;

- boiler steam capacity (load);

- fuel consumption;

- temperature of feed water;

- $\quad$ steam pressure in the boiler drum;

- excess air.

At the same time, one of the main channels of the object is the channel "fuel consumption - pressure of superheated steam", which is decoupled from others. Therefore, it is for him that we will calculate the automatic control system (ACS) [ 8]. [9]:

The transfer function of the object along the channel under consideration has the form

$$
W(p)=\frac{0.4 \cdot e^{-0.7 p}}{4.62 p^{2}+4.3 p+1}
$$

Applying the expansion in the 1st order Pade series, we obtain:

$$
\begin{aligned}
& W(p)=\frac{0.4 \cdot(1-0.35 p)}{\left(4.62 p^{2}+4.3 p+1\right) \cdot(1+0.35 p)}=\frac{0.4-0.14 p}{1.6 p^{3}+6.1 p^{2}+4.7 p+1}= \\
& =\frac{0.25-0.09 p}{p^{3}+3.8 p^{2}+2.9 p+0.6}
\end{aligned}
$$

Taking into account the transfer functions of the sensor and the working body, we have:

$$
\begin{aligned}
& W_{o \sigma}(p)=W(p) \cdot W_{\partial}(p) \cdot W_{p o}(p)=\frac{(0.25-0.09 p) \cdot \frac{20}{160} \cdot \frac{7500}{30 \cdot 60}}{p^{3}+3.8 p^{2}+2.9 p+0.6}= \\
& =\frac{(0.25-0.09 p) \cdot 0.125 \cdot 4.2}{p^{3}+3.8 p^{2}+2.9 p+0.6}=\frac{0.13-0.047 p}{p^{3}+3.8 p^{2}+2.9 p+0.6}
\end{aligned}
$$

We write the transfer function (3) in matrix form:

$$
\begin{aligned}
& \dot{x}(t)=\left[\begin{array}{ccc}
0 & 1 & 0 \\
0 & 0 & 1 \\
-0.6 & -2.9 & -3.8
\end{array}\right] \cdot x(t)+\left[\begin{array}{l}
0 \\
0 \\
1
\end{array}\right] \cdot u(t) \\
& y(t)=\left[\begin{array}{lll}
0.13 & -0.047 & 0
\end{array}\right] \cdot x(t)
\end{aligned}
$$

Let's introduce the notation:

$$
A=\left[\begin{array}{ccc}
0 & 1 & 0 \\
0 & 0 & 1 \\
-0.6 & -2.9 & -3.8
\end{array}\right] ; B=\left[\begin{array}{l}
0 \\
0 \\
1
\end{array}\right] ; C=\left[\begin{array}{lll}
0.13 & -0.047 & 0
\end{array}\right] .
$$

Then the system of equations (4) will take the form:

$$
\begin{aligned}
& \dot{x}(t)=A \cdot x(t)+B \cdot u(t) \\
& y(t)=C \cdot x(t)
\end{aligned}
$$

Proceeding from the fact that it is necessary that at low energy consumption we get a high-quality transient process, we will form the functional []: 


$$
J=\int_{0}^{\infty}\left(X^{T} Q X+u^{T} R u\right) d t
$$

where $Q=\left(\begin{array}{lll}1 & 0 & 0 \\ 0 & 1 & 0 \\ 0 & 0 & 1\end{array}\right) ; R=1$.

Then it is necessary to find a linear feedback $u=u(x)$, minimizing functional (7).

The optimal feedback will look like:

$$
u=-R^{-1} B^{T} K^{T} x
$$

where $\mathrm{K}$ is a positive definite symmetric matrix that is a solution to the Riccati equation:

$$
\begin{gathered}
Q=K B R^{-1} B^{T} K^{T}+A^{T} K^{T}+K A \\
\mathrm{P}: \\
K=\left(\begin{array}{lll}
2.72 & 2.57 & 0.57 \\
2.57 & 4.26 & 0.91 \\
0.57 & 0.91 & 0.36
\end{array}\right)
\end{gathered}
$$

From here, using equation (6), we find the desired feedback:

$$
u=-\left[\begin{array}{lll}
0 & 0 & 1
\end{array}\right] \cdot\left(\begin{array}{ccc}
2.72 & 2.57 & 0.57 \\
2.57 & 4.26 & 0.91 \\
0.57 & 0.91 & 0.36
\end{array}\right) \cdot\left(\begin{array}{l}
x_{1} \\
x_{2} \\
x_{3}
\end{array}\right)=-0.57 x_{1}-0.91 x_{2}-0.36 x_{3}
$$

The response of the system to a stepwise disturbance is shown in Fig. 1. It can be seen from the figure that the system completely suppresses the disturbing effect, and in an admissible time. [ 10] However, the technical implementation of the designed system encounters a number of difficulties associated with the impossibility of measuring all state variables, namely $\dot{x}_{1}, \ddot{x}_{1}$ and $\dddot{x}_{1}$.

Therefore, to implement the synthesized control algorithm, those state variables that cannot be directly measured must be calculated, for which we synthesize a state observer. 


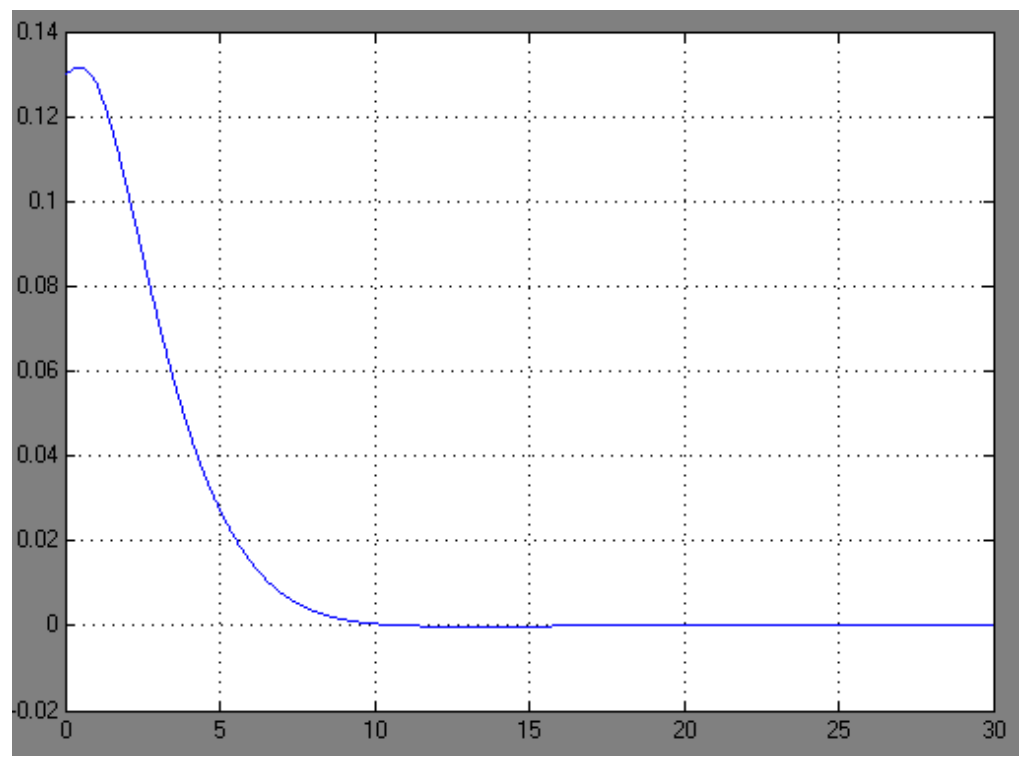

Fig. 1. Object response to stepwise disturbance.

State Observer Synthesis

In the assessment process, we will use all available information, i.e. the input signal $u(t)$, the measured value of the output signal $y(t)$ and the matrix of the system A, B and C. The state evaluator, called the state observer, has the same dynamics as the system itself and can be represented by the following equation:

$$
\dot{\hat{x}}(t)=F \cdot \hat{x}(t)+H \cdot u(t)+G \cdot y(t)
$$

Matrices F, H and G are chosen so that they give $\hat{x}(t)$ an accurate estimate $x(t)$. Then, in the control system $\hat{x}(t)$, the vector is used to generate a feedback signal (7).

According to [11], the state observer matrices are found as follows:

$$
\begin{aligned}
& F=A-G C \\
& H=B
\end{aligned}
$$

Taking this into account, equation (8) takes the form:

$$
\dot{\hat{x}}(t)=(A-G C) \cdot \hat{x}(t)+B \cdot u(t)+G \cdot y(t)
$$

where the unknown matrix $\mathrm{G}$ is defined as follows:

$$
G=a_{e}(A) \cdot\left[\begin{array}{c}
C \\
C A \\
C A^{2}
\end{array}\right]^{-1} \cdot\left[\begin{array}{l}
0 \\
0 \\
1
\end{array}\right]
$$

where $a_{e}(A)$ is the matrix polynomial formed by using the coefficients of the desired characteristic equation $a_{e}(s)$, i.e. 


$$
a_{e}(A)=A_{e} \cdot\left(A^{2}+A+1\right)
$$

where $A_{e}=A-B R^{-1} B^{T} K^{T}$ - matrix of coefficients of the closed-loop system.

Substituting the corresponding values, we get [12]:

$$
A_{e}=\left(\begin{array}{ccc}
0 & 1 & 0 \\
0 & 0 & 1 \\
-1.166 & -3.813 & -4.155
\end{array}\right)
$$

Then, by equation (14), we obtain:

$$
a_{e}(A)=\left(\begin{array}{ccc}
0.566 & 0.913 & 0.355 \\
-0.213 & -0.464 & -0.436 \\
0.262 & 1.051 & 1.193
\end{array}\right)
$$

Then, using expression (13), we find the required matrix:

$$
G=\left[\begin{array}{c}
-1.968 \\
11.5778 \\
-34.785
\end{array}\right]
$$

Substituting the found matrix into equation (12), we obtain the required coordinates:

$$
\left\{\begin{array}{l}
\dot{\hat{x}}_{1}=0.256 \cdot x_{1}+0.908 \cdot x_{2}-1.968 \cdot y \\
\dot{\hat{x}}_{2}=-1.505 \cdot x_{1}+0.544 \cdot x_{2}+x_{3}+11.578 \cdot y \\
\dot{\hat{x}}_{3}=3.922 \cdot x_{1}-4.535 \cdot x_{2}-3.8 x_{3}+u-34.785 \cdot y
\end{array}\right.
$$

The combined graphs of transient processes in systems with and without a state observer are shown in Fig. 2. [13]. As you can see, the graphs almost coincide, therefore, the observer is synthesized correctly. 


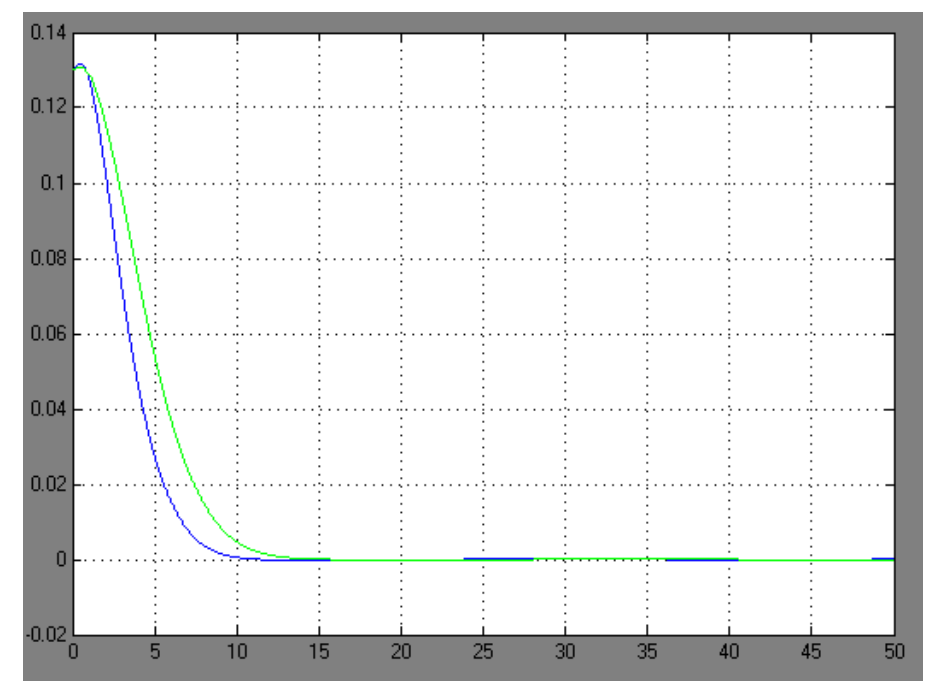

Fig. 2. Combined graphs of transient processes.

The synthesized system sufficiently effectively suppresses disturbing influences, but is practically not adapted to work along the control channel and is characterized by a significant static error, to eliminate which, in accordance with the classical theory of automatic control, it is necessary to include an integrator in the direct channel, which will correspond to proportional-integral control [ 14,15]:

$$
\dot{x}_{4}(t)=C x(t)-r(t)
$$

where $r(t)$ is the input action.

Object input:

$$
u(t)=-K x(t)-K_{4} x_{4}
$$

then

$$
\dot{x}(t)=A x(t)-B K x(t)-B K_{4} x_{4}
$$

The state vector of the feedback system has the form:

$$
\dot{x}_{a}(t)=\left(\begin{array}{c}
\dot{x}(t) \\
\dot{x}_{4}(t)
\end{array}\right)=\left[\begin{array}{cc}
A & 0 \\
C & 0
\end{array}\right] \cdot\left[\begin{array}{c}
x(t) \\
x_{4}(t)
\end{array}\right]-\left[\begin{array}{cc}
B K & B K_{4} \\
0 & 0
\end{array}\right] \cdot\left[\begin{array}{c}
x(t) \\
x_{4}(t)
\end{array}\right]+\left[\begin{array}{c}
0 \\
-1
\end{array}\right] \cdot r(t)
$$

This equation can be given a different form [ 16]:

$$
\dot{x}_{a}(t)=A_{a} \cdot x_{a}(t)-B_{a} K_{a} \cdot x_{a}(t) \cdot+\left[\begin{array}{c}
0 \\
-1
\end{array}\right] \cdot r(t)
$$

where $A_{a}=\left[\begin{array}{cc}A & 0 \\ C & 0\end{array}\right] ; B_{a}=\left[\begin{array}{c}B \\ 0\end{array}\right] ; K_{a}=\left[\begin{array}{ll}K & K_{4}\end{array}\right]$.

Then the problem is posed of finding a feedback for an object with modified matrices A and B. For this, we use the above technique [17]::

Extended object matrices are: 


$$
A_{a}=\left[\begin{array}{cccc}
0 & 1 & 0 & 0 \\
0 & 0 & 1 & 0 \\
-0.6 & -2.9 & -3.8 & 0 \\
0.13 & -0.047 & 0 & 0
\end{array}\right] ; B_{a}=\left[\begin{array}{l}
0 \\
0 \\
1 \\
0
\end{array}\right]
$$

Carrying out calculations similar to the above, we obtain the matrix K [18]:

$$
K=\left[\begin{array}{cccc}
4.7828 & 4.4705 & 1.0166 & 4.8213 \\
4.4705 & 6.0425 & 1.3368 & 4.2560 \\
1.0166 & 1.3368 & 0.4560 & 1 \\
4.8213 & 4.2560 & 1 & 12.4357
\end{array}\right] .
$$

Then the desired feedback has the form:

$$
u_{a}=-1.017 x_{1}-1.337 x_{2}-0.456 x_{3}-x_{4}
$$

The transient process along the control channel is shown in Fig. 3, and the combined transient process along the disturbance channel is shown in Fig. 4.

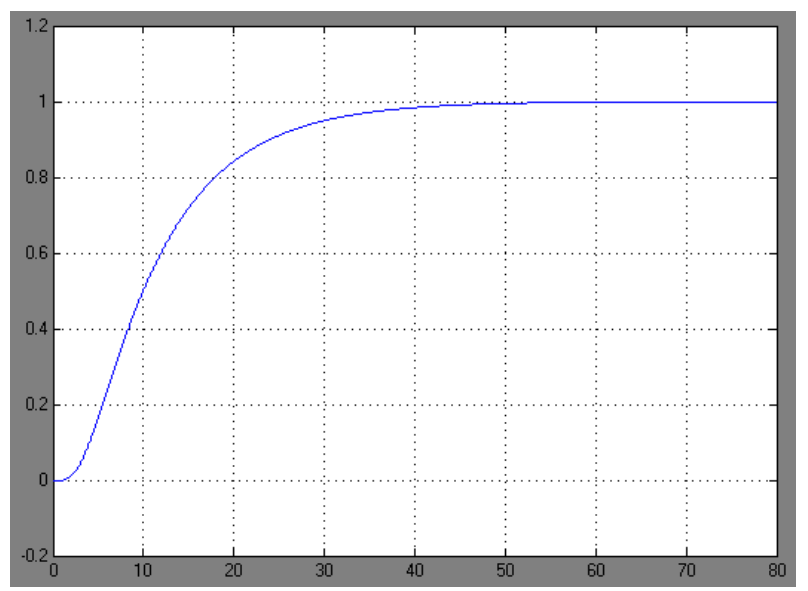

Fig. 3. Transient process of the system along the control channel. 


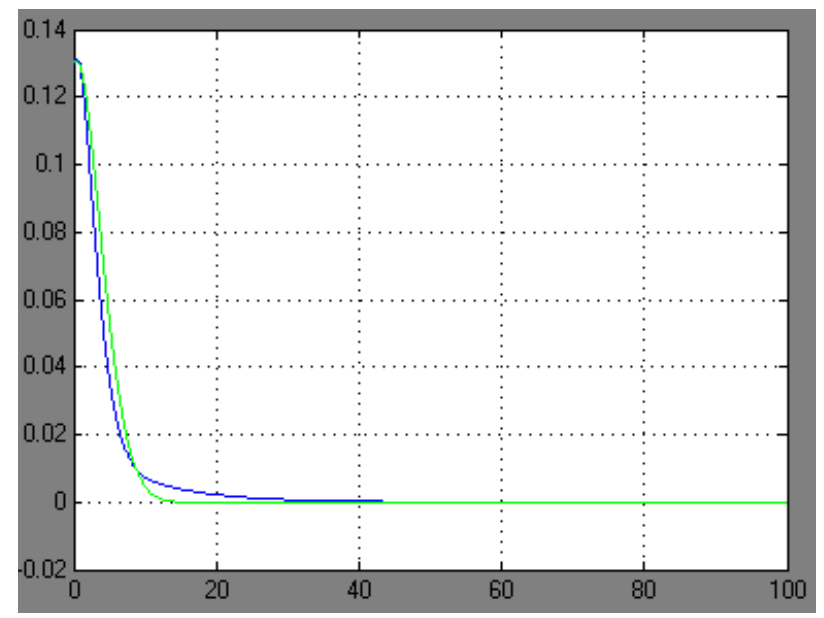

Fig. 4. Combined transient processes along the disturbance channel.

Analysis of the simulation results shows that the synthesized system is characterized by zero static error both in the control channel and in the disturbance channel, while maintaining the dynamics of disturbance suppression. However, given that the state variables involved in the formation of the regulation law are not measured, but calculated on the basis of the object model, which, as a rule, is adequate to the real control object only to a certain extent, it seems appropriate to assess the robustness of the designed system [ 19].

Figure 5a-e shows the transient processes in a closed system with a two-fold variation of the coefficients of the matrix A. Analyzing the given transient characteristics, we can conclude that the synthesized automatic control system is rather rough, since when the time constants of the object change, the quality indicators of the transient processes remain admissible (no static error, the amount of overshoot is admissible, the processes are steady) [20]:

\section{Conclusions}

The synthesized system realizes optimal control of a double-drum water-tube boiler with natural circulation with effective suppression of disturbing influences and ensuring astatism of the control channel. By the method of mathematical modeling, its performance was confirmed with a two-fold variation of the model parameters, which indicates the possibility of moving from model to physical tests of the proposed control algorithm.

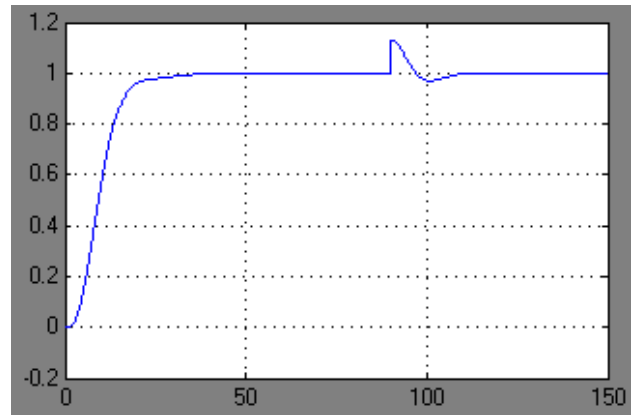

a) $\mathrm{a}_{3}=2 \mathrm{a}_{3}^{0}$

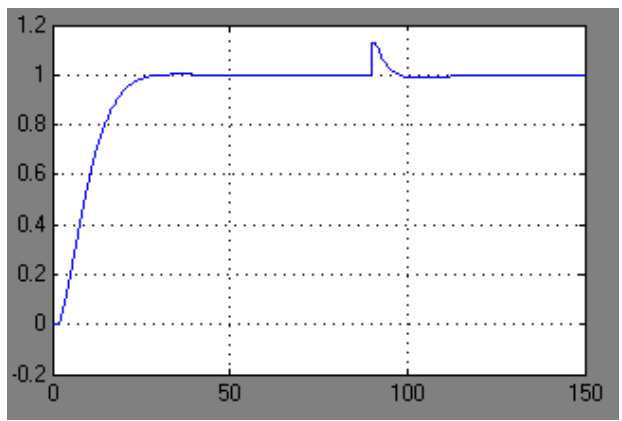

b) $\mathrm{a}_{3}=0.5 \mathrm{a}_{3}^{0}$ 


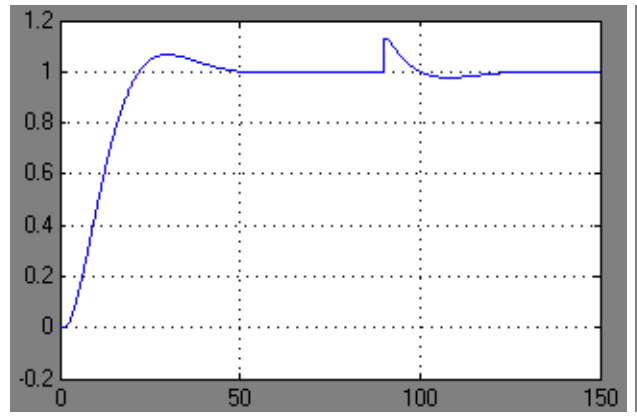

c) $\mathrm{a}_{2}=2 \mathrm{a}_{2}^{0}$

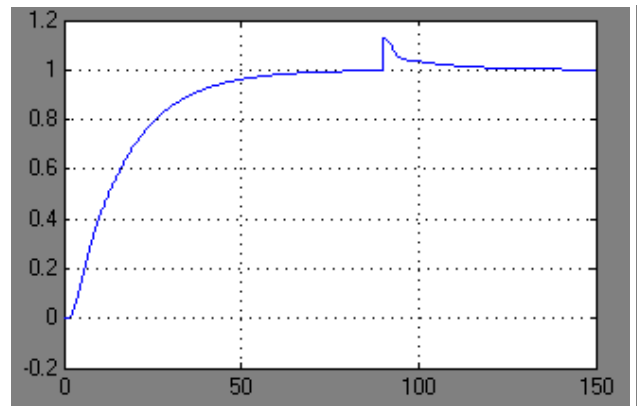

e) $\mathrm{a}_{1}=2 \mathrm{a}_{1}^{0}$

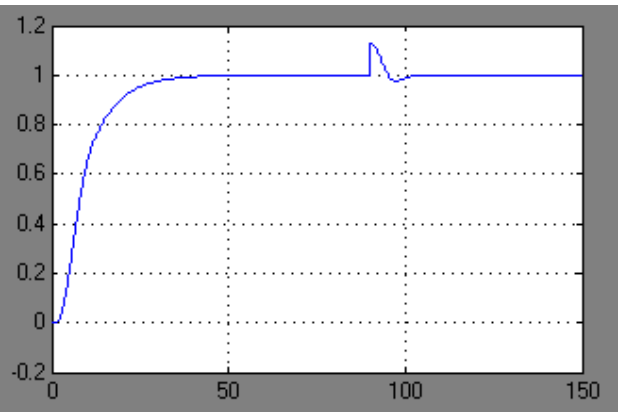

d) $\mathrm{a}_{2}=0.5 \mathrm{a}_{2}^{0}$

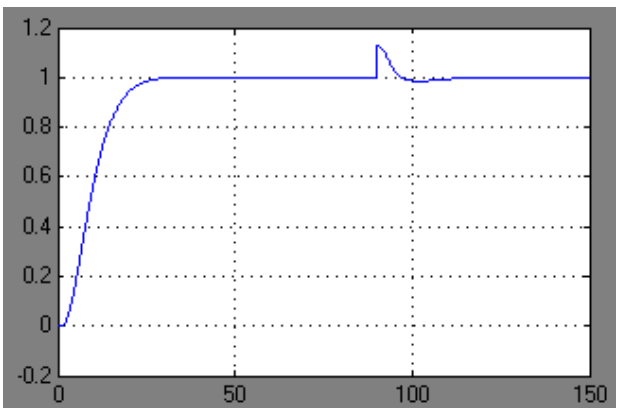

f) $\mathrm{a}_{1}=0.5 \mathrm{a}_{1}^{0}$

Fig. 5. Transient processes in a closed system when varying the parameters of the control object.

\section{References}

1. V.N. Volkova, A.V. Loginova, E.N. Desyatirikova, V.E. Belousov, V.V. Chugunov, Proceedings of the conference of young researchers in electrical and electronic engineering IEEE 2018, ElConRus 2018, 1293-1297 (2018)

2. V.I. Lutin, E.N. Desyatirikova, O.V. Kurripta, N.V. Akamsina, V.E. Mager, Proceedings of the conference of young researchers of electrical and electronic engineering IEEE 2018, ElConRus 2018, 1113-1116 (2018) DOI: 10.1109 / EIConRus.2018.8317285

3. M. Zherlykina, E. Smorodina, G. Kalabukhov, A. Smolyaninov, 13th International Scientific and Practical Conference "State and Prospects for the Development of Agribusiness", INTERAGROMASH 2020, E3S Web of Conferences 175, 11017 (2020) DOI: 10.1051 / e3sconf / 202017511017

4. A.V. Smolyaninov, I.V. Potsebneva, L.V. Chernenkaya, International Russian Conference on Automation 2019 (RusAutoCon) (2019) DOI: 10.1109 / RUSAUTOCON.2019.8867604

5. E.N. Desyatirikova, V.I. Akimov, D.V. Sysoev, V.E. Mager, L.V. Chernenkaya, Materials of the conference of young scientists in the field of electrical and electronic engineering IEEE 2019, ElConRus 2019 8657217, 474-477 (2019)

6. E.N. Desyatirikova, A.V. Vasilenko, A.V. Polukazakov, V.E. Mager, L.V. Chernenkaya, Materials of the conference of young scientists in the field of electrical and electronic engineering IEEE 2019, ElConRus 2019 86570545, 471-473 (2019) 
7. V.I. Akimov, A.V. Polukazakov, N.V. Sitnikov, International Russian Conference on Automation $2019 \quad$ (RusAutoCon) (2019) DOI: 10.1109 / RUSAUTOCON.2019.8867651

8. V.I. Akimov, A. Polukazakov, V.P. Shelyakin, International Russian Conference on Automation $2019 \quad$ (RusAvtoKon) (2019) DOI: 10.1109 / RUSAUTOCON.2019.8867777

9. M.Ya. Panov, G.N. Martynenko, V.V. Ukhlova, A.I. Kolosov, Izvestia of Higher Educational Institutions, Series of Technologies of the Textile Industry 1, 239-243 (2017)

10. V.N. Melkumov, S.V. Chuikin, K.A. Sklyarov, A.I. Kolosov, Indian Journal of Science and Technology 9(18) (2016)

11. B.P. Novoseltsev, M.N. Zherlykina, K.V. Garmonov, IOP Conference Series: Materials Science and Engineering 962(3), 032003 (2020)

12. E.N. Desyatirikova, L.V. Chernenkaya, V.E. Mager, Proceedings of the international conference on automation, RusAvtoKon 20198867814 (2019)

13. E.N. Desyatirikova, L.V. Chernenkaya, V.E. Mager, Russian Conference on Automation, RusAutoCon $2018 \mathbf{8 5 0 1 7 4 7}$ (2018)

14. G.N. Kravchenko, Yu.I. Popov, K.G. Kravchenko, IOP Conference: Materials Science and Engineering 734(1), 012014 (2019)

15. Yu.I. Bityukov, Yu.I. Deniskin, Dynamics 7818981 (2016)

16. I.M. Artamonov, A.R. Deniskina, Y.I. Deniskin, Protective materials of the XIX AllRussian Scientific and Technical Conference, 57-61 (2018)

17. E.N. Desyatirikova, L.V. Chernenkaya, V.E. Mager, Proceedings of the International Russian Conference on Automation, RusAvtoKon 20198867814 (2019)

18. C.C.M. Tavares, R.T. Batista, R.V. Landim, J.A.C. Velasco, L.F. Senna, Analysis of technical failures 113, 104553 (2020)

19. E.N. Desyatirikova, L.V. Chernenkaya, V.E. Mager, Proceedings - 2020 International Russian Conference on Automation, RusAutoCon 2020 9208106, 493-499 (2020)

20. N. Martynov, et al. E3S Web of Conferences, 203, 04011 (2020) doi:10.1051/e3sconf/202020304011 